\title{
Compositional characterization of iron gall inks in manuscripts
}

\author{
Viegas, R. ${ }^{* * *}$, Franco, N. ${ }^{*}$, Alves, L.C. ${ }^{* * *},{ }^{* * * *}$, Peña, M. T. ${ }^{* *}$, Alves, E. ${ }^{*}$ and Corregidor, V. ${ }^{*}$ \\ * IPFN, IST/CTN, Universidade de Lisboa, E.N. 10, 2686-953 Sacavém, Portugal \\ ** CFTP, Instituto Superior Técnico, Universidade de Lisboa, Lisboa, Portugal \\ **** CFNUL, Universidade de Lisboa, Av. Prof. Gama Pinto, 2, 1649-003 Lisboa, Portugal \\ **** C2TN, IST/CTN, Universidade de Lisboa, E.N. 10, 2686-953 Sacavém, Portugal
}

Email: vicky.corregidor@ctn.ist.utl.pt

When dealing with historical artifacts, non-destructive analytical methods for characterization are imperative. Proton Induced X-ray Emission (PIXE), when using an external micro beam, is considered to be an efficient technique for studying historical documents [1]. Besides the high sensitivity of this technique, the small dimension of the beam jointly with the raster capabilities of the set-up [2] allows the examination of specific parts of the document and also the study of the ink composition and distribution over the paper, which proved to be a great advantage when analyzing ink spots of the documents.

In this work, it will be presented the results of the compositional study of iron gall ink which is present in a document dated from the beginning of the XX century. Nondestructive characterization techniques as photographs under infrared (IR) and ultraviolet (UV) illumination, PIXE, and X-ray diffraction (XRD) were used. Figure 1 presents the IR and UV photographs from a segment of the document. Under IR illumination, the whole document shows an homogeneous signal and it was not possible to point out the presence of different inks. Through UV illumination it is possible to detect ink spread, which is especially noticeable in the numbers. This effect (also visible under IR light) may be due to the excess of ink in those regions, being in fact, the most corroded regions of the document. The main responsible for this corrosion phenomenon are the Fe ions, which are present in these inks as one of the major constituents, jointly with $\mathrm{S}$, mainly because the iron sulphate is one of ingredients of the basic recipe. Other ingredients are Arabic gum, tannin acid and water. Therefore the results of PIXE analysis indicate that the ink is composed by minor amounts of $\mathrm{Cu}, \mathrm{Zn}$, $\mathrm{Sr}$ and $\mathrm{Ba}$ (besides $\mathrm{Fe}, \mathrm{S}$ and $\mathrm{Ca}$ ). These minor elements are critical to distinguish between different inks, even in the same document [2] which was not the case for this document. Figure 2 shows the elemental distribution maps for selected elements, and it is clear how $\mathrm{Fe}$ and $\mathrm{Cu}$ signals are higher in inked areas while Ca signal has an homogeneous distribution all over the scan.

By XRD it was not possible to detect any of the compounds characteristic of the ink, probably because of the small quantity (fig. 3). XRD diffractograms from inked and non-inked areas are quite similar, and they show the compounds present in paper, such as cellulose, kaolin, calcite and anhydrite [3], which are used as fillers or as paper loading materials.

Future work will involve the use of Rutherford Backscattering Spectrometry to study the ink depth distribution and the reproduction of iron gall inks to be studied by XRD.

V. Corregidor acknowledges the funding support from the FCT-Ciência program. The work was partially supported by FCT-Portugal (PEST-OE/FIS/UI0275/2011). M.T. Peña acknowledges CFTP-FCT (PestOE/FIS/UI0777/2013). Special thanks to R. Winstanley for sharing with us his collection.

[1] L. Giuntini, et al., Nucl. Instrum. and Meth. B., 95, 389-392, 1995.

[2] R. Viegas, et al., International Journal of Conservation Science, 4, 593-602, 2013.

[3] N. Terinte, et al., Lenzinger Berichte, 89, 118-131, 2011. 


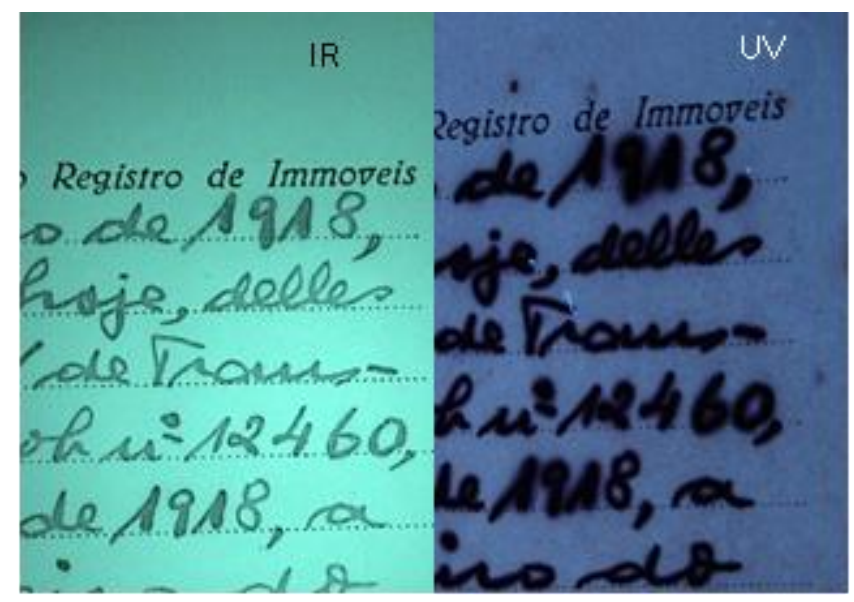

Figure 1. IR and UV photographs of the document dated from the beginning of the XX century.

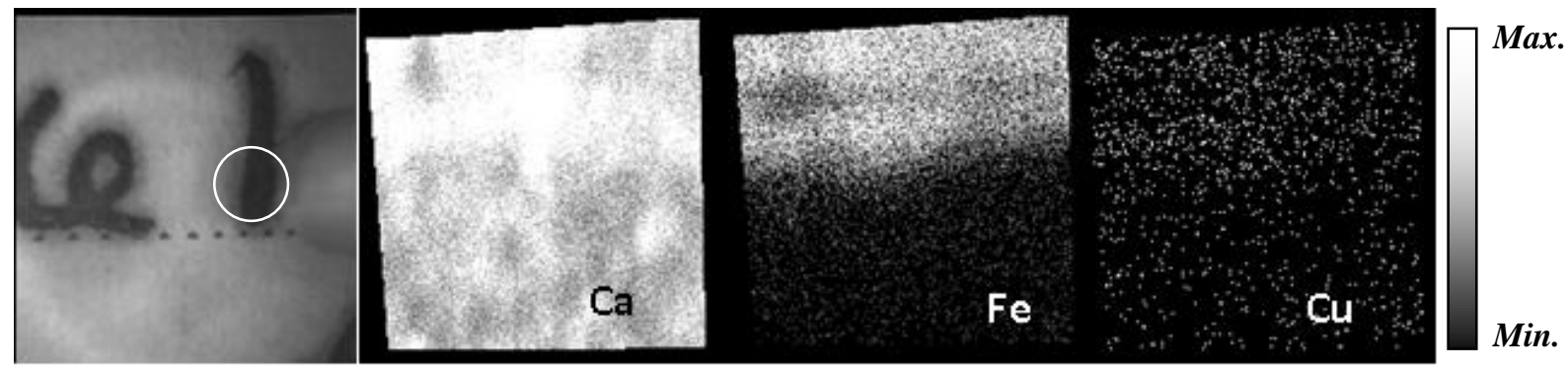

Figure 2. 2D elemental maps $\left(800 \times 800 \mu \mathrm{m}^{2}\right)$ recorded in the area partially inked (shown in the photograph).

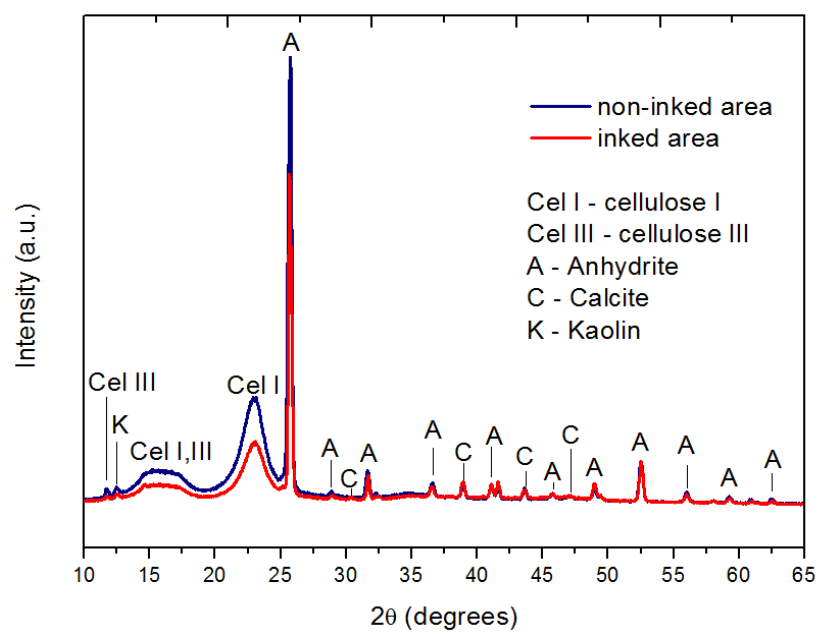

Figure 3. XRD diffractograms recorded in an inked and a non-inked area of the document. 